\title{
Long-term control of vancomycin-resistant Enterococcus faecium at the scale of a large multihospital institution: a seven-year experience
}

S Fournier (sandra.fournier@sap.aphp.fr) ${ }^{1}$, F Brossier², N Fortineau³ , F Gillaizeau ${ }^{4}$, A Akpabie $^{5}$, A Aubry $^{6}$, F Barbut ${ }^{7}$,

F X Chedhomme ${ }^{8}$, N Kassis-Chikhani ${ }^{9}$, J C Lucet $^{10}$, J Robert ${ }^{2}$, D Seytre ${ }^{11}$, I Simon ${ }^{12}$, D Vanjak ${ }^{13}$, J R Zahar ${ }^{14}$, C Brun-Buisson ${ }^{15}$, V Jarlier ${ }^{1,2}$

1. Direction de la Politique Médicale (Directorate of Medical Politics), Assistance Publique-Hôpitaux de Paris, Paris, France

2. Bacteriology laboratory, Université Pierre et Marie CURIE - Paris 6, Hôpital Pitié-Salpêtrière, Assistance publique Hôpitaux de Paris, Paris, France

3. Bicêtre Hospital, Assistance publique - Hôpitaux de Paris, Kremlin-Bicêtre, France

4. Departement of hospital informatics, European hospital Georges Pompidou, Assistance publique - Hôpitaux de Paris, Paris, France

5. Emile Roux Hospital, Assistance publique - Hôpitaux de Paris, Limeil-Brévannes, France

6. Charles Foix Hospital, Assistance publique - Hôpitaux de Paris, Ivry-Sur-Seine, France

7. Saint Antoine Hospital, Assistance publique - Hôpitaux de Paris, Paris, France

8. La Collégiale Hospital, Assistance publique - Hôpitaux de Paris, Paris, France

9. Paul Brousse Hospital, Assistance publique - Hôpitaux de Paris, Villejuif, France

10. Bichat-Claude Bernard Hospital, Assistance publique - Hôpitaux de Paris, Paris, France

11. Avicenne Hospital, Assistance publique - Hôpitaux de Paris, Bobigny, France

12. Sainte Périne Hospital, Assistance publique - Hôpitaux de Paris, Paris, France

13. Beaujon Hospital, Assistance publique - Hôpitaux de Paris, Beaujon, France

14. Necker Hospital, Assistance publique - Hôpitaux de Paris, Paris, France

15. Henri Mondor Hospital, Assistance publique - Hôpitaux de Paris, Créteil, France

Citation style for this article:

Fournier S, Brossier F, Fortineau N, Gillaizeau F, Akpabie A, Aubry A, Barbut F, Chedhomme FX, Kassis-Chikhani N, Lucet JC, Robert J, Seytre D, Simon I, Vanjak D, Zahar JR, Brun-Buisson C, Jarlier V. Long-term control of vancomycin-resistant Enterococcus faecium at the scale of a large multihospital institution: a seven-year experience. Euro Surveill. 2012;17(30):pii=20229. Available online: http://www.eurosurveillance.org/ViewArticle.aspx?Articleld=20229

Article submitted on 17 January 2012 / published on 26 July 2012

Repeated outbreaks of vancomycin-resistant Enterococcus faecium (VRE) occurred between 2004 and 2010 in Assistance Publique - Hôpitaux de Paris (AP-HP), a 23,000-bed multi-hospital institution. From August 2004 to December 2005, the French guidelines for preventing cross-transmission of multiresistant bacteria were applied. Because the number of VRE cases continued to increase, an institutional control programme was implemented from January 2006 onwards: It foresees stopping transfer of VRE and contact patients, separating VRE and contact patients in distinct cohorts, intervention of a central infection control team to support local teams, and quick application of measures as soon as first VRE cases are identified. Between August 2004 and December 2010, 45 VRE outbreaks occurred in 21 of the 38 AP-HP hospitals, comprising 533 cases. Time series analysis showed that the mean number of cases increased by 0.8 cases per month ( $95 \%$ confidence interval $(\mathrm{Cl}): 0.3$ to $1.3, p=0.001$ ) before, and decreased by 0.7 cases per month after implementation of the programme ( $95 \% \mathrm{Cl}:-0.9$ to $-0.5, \mathrm{p}<0.001$ ), resulting in a significant trend change of -1.5 cases per month $(95 \% \mathrm{Cl}$ : -2.1 to -0.9 , p (0.001). The number of cases per outbreak was significantly lower after implementation of the programme. A sustained and coordinated strategy can control emerging bacteria at the level of a large regional multihospital institution.

\section{Introduction}

Outbreaks of vancomycin-resistant Enterococcus faecium (VRE) occurring in hospitals represent a major problem in many countries [1]. The documented transfer of vancomycin resistance to methicillin-resistant Staphylococcus aureus (MRSA) strains is an additional reason for controlling the spread of VRE [2], especially in countries such as France where MRSA rates are high [3]. VRE have become endemic in the United States despite introduction in 1995 of national guidelines by the Centers for Disease Control and Prevention [4,5]. In France, the rate of asymptomatic VRE carriage at hospital admission was $0.3 \%$ in a national study conducted in 2006, showing that VRE are not endemic in the general population [6]. However, several VRE outbreaks have been reported in French hospitals during the last few years [7-9]. One of these outbreaks started in 2004 in one of the 38 hospitals of the Assistance Publique - Hôpitaux de Paris (AP-HP), the largest healthcare institution in France [7]. The present study describes the VRE infection control programme that allowed controlling the outbreaks that emerged between 2004 and 2010 in this large multihospital institution that serves 11.6 million inhabitants. 


\section{Methods}

\section{Setting}

The AP-HP is a public health institution that administers 38 teaching hospitals (23 acute care (AC) and 15 rehabilitation/long-term care (RLTC) hospitals). AP-HP has a total of 23,000 beds, representing $36 \%$ of all hospital beds in the île de France region that encompasses the city of Paris, suburbs and surrounding counties, and counts 11.6 million inhabitants. AP-HP admits approximately 1 million inpatients per year. Administrators and medical committees manage AP-HP hospitals locally, but decisions on large investments and medical developments are taken by the central administration. A local infection control team is in charge of prevention and surveillance of nosocomial infections in each hospital, but actions of foremost importance for the whole institution, such as the multidrug-resistant bacteria control programme, are coordinated centrally by a multidisciplinary infection control team (one infectious disease physician, one bacteriologist, one epidemiologist and one nurse) [10]. Until August 2004, VRE cases were scarce in this institution where surveillance of multidrug-resistant bacteria (such as extended-spectrum beta-lactamase-producing enterobacteria, methicillin-resistant Staphylococcus aureus or VRE) has been implemented in the early 1990 s [11].

\section{Case definitions}

VRE infection was defined as any patient with a VRE isolated from a clinical specimen, VRE colonisation was defined as any patient with a VRE isolated from a rectal swab. A VRE case was defined as any infected or colonised patient. A contact patient was defined as any patient whose stay overlapped with the stay of a VRE case for at least one day in the same unit. An outbreak was defined as at least two VRE cases (i.e. one index case and at least one secondary case among the contact patients) occurring in a given hospital, with a clear epidemiological link (stay during the same period of time in the same unit) and involving the same VRE strain based on species, van gene, antibiotic susceptibility and pulsed-field gel electrophoresis (PFGE) pattern. During the follow-up of each outbreak, the occurrence of a new case sharing the same strain, as defined by the above criteria, was considered as part of the same outbreak if the time between the discharge of previous cases and the detection of the new case was less than three months.

\section{VRE control programme}

Three consecutive periods were distinguished based on the VRE control measures. During period 1 (August 2004 to December 2005), referred to as the 'VRE emerging period', the French national guidelines for preventing cross-transmission of multidrug-resistant bacteria, designed mainly for curbing MRSA rates [1], were applied as follows: (i) barrier precautions around VRE cases, and (ii) identification of VRE carriers (screening) by culturing rectal swabs from contact patients present in the unit.
In period 2 (January 2006 to December 2007), referred to as the 'Intervention period, an institutional VRE programme was designed and coordinated by the AP-HP central infection control team in response to a steady increase in the monthly number of cases that had occurred during period 1. This programme emphasised rapid and stringent application of organisational procedures as soon as a first VRE case was identified, as well as the commitment of the hospital management. During this period, the programme included the two measures already applied in period 1, but also a bundle of seven new measures, as follows:

- rapid reporting of every new VRE case to the AP-HP central infection control team,

- stopping transfers of cases and contact patients to other units of the hospital or to any other hospitals,

- particular attention to daily cleaning of VRE patient environments with disinfectant,

- extended VRE screening of contact patients to those already discharged or transferred from the involved unit after identification of index case,

- maintained screening of all contact cases until the outbreak was considered controlled, i.e. after all VRE cases have been discharged and after a period of at least three months without a new case,

- identifying discharged VRE and contact patients in case of readmission,

- and cohorting patients in three distinct areas with dedicated nursing staff: 'VRE patients' section, the 'Contact patients' section and the 'VRE-free patients' section for newly admitted patients with no previous contact with VRE patients.

To stimulate the efforts made by the local infection control teams and administrators, the central infection control team followed the number of new cases, of new outbreaks, difficulties in programme implementation, and regularly disseminated results within hospitals and central administration. Moreover, the central infection control team visited the hospitals regularly to help the local teams in applying the VRE programme.

In period 3 (January 2008 to December 2010), referred to as 'Consolidation period', the VRE programme was routinely applied by local teams well trained on every aspect of the programme. The AP-HP central infection control team intervened only when local teams had difficulties in controlling outbreaks.

\section{Microbiological methods}

Culture of rectal swabs was performed on selective media containing $6 \mathrm{mg} / \mathrm{L}$ vancomycin [12]. The API 20 Strep gallery (bioMérieux, Marcy L’Etoile, France) and GenoType Enterococcus assay (Hain Lifescience, Bandol, France) were used to confirm the identification of $E$. faecium. The latter genotypic method also allowed identification of which vancomycin resistance gene was involved (vanA or vanB) and was performed as early as possible at the local level or in an AP-HP 


\section{FIGURE 1}

Dendrogram of vancomycin-resistant Enterococcus strains involved in hospital outbreaks, Assistance Publique-

Hôpitaux de Paris, August 2004-December 2007 (n=23)

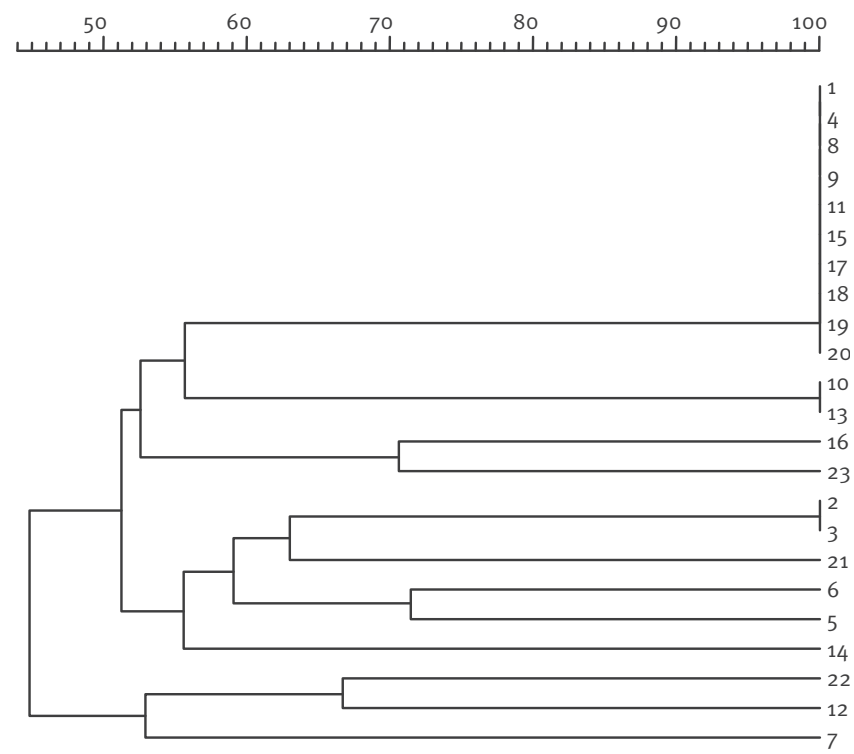

Produced by Dice analysis of the pulsed-field gel electrophoresis patterns and unweighed pair-group method with arithmetic averages. Percent similarities between strains are shown. Outbreaks are numbered in chronological order.

\section{FIGURE 2}

Pulsed-field gel electrophoresis patterns of vancomycinresistant Enterococcus strains involved in hospital outbreaks, Assistance Publique-Hôpitaux de Paris, August 2004-December $2007(n=23)$

A

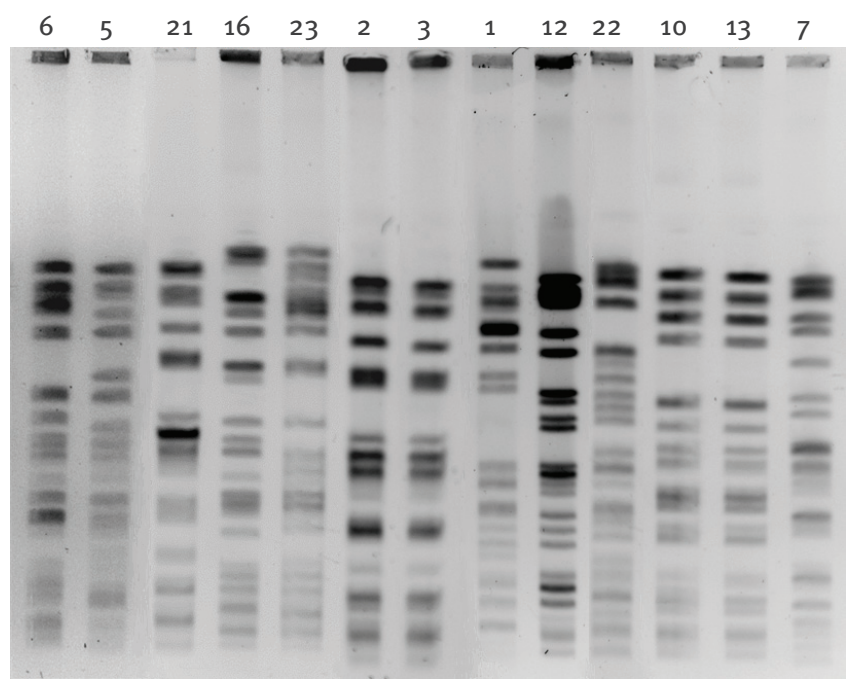

B

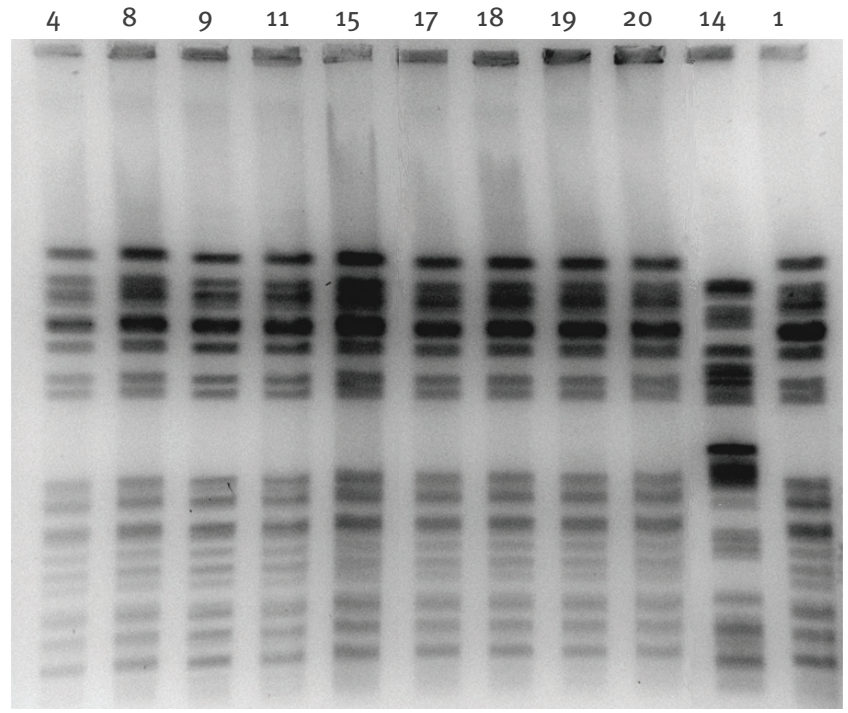

The strains sharing the same pattern (see Figure 1) are: 2 and $3 ; 10$ and $13 ; 1,4,8,9,11,15,17,18,19$, and 20.

the intervention after implementation of the VRE programme, both immediately and over time [18]. The model assumed a linear relationship between time and the number of new cases in each period, allowing for an abrupt change in level immediately after the start of the intervention and a change in the trend (estimated as the difference between pre-intervention and intervention slopes). From the model obtained in period 1 , 
Timeline of successive hospital outbreaks of vancomycin-resistant Enterococcus, Assistance Publique-Hôpitaux de Paris, August 2004-December $2010(n=45)$

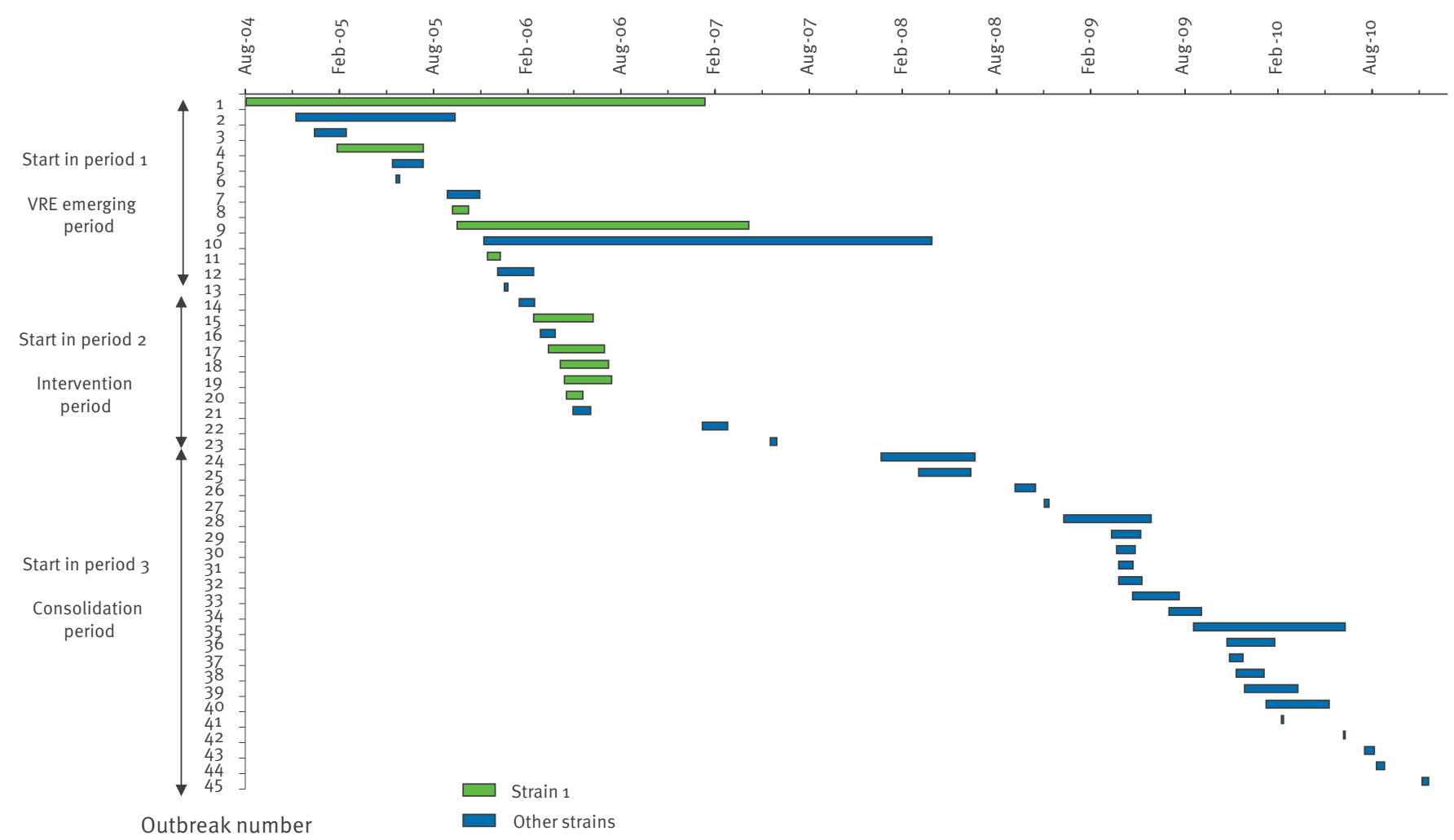

Each outbreak is represented by a line indicating the time between the date of detection of the first and the last case. Outbreaks due to strain 1 are coloured in green. This figure shows the temporal overlap of the 10 outbreaks caused by this particular strain in eight distinct hospitals.

we calculated the expected monthly number of new cases during period 2 with $95 \%$ confidence intervals (Cl). This method produces a simple representation of what would have happened if no further intervention had occurred and allows comparing expected with observed values.

The median number of cases in each outbreak was presented with its interquartile range (IQR) and compared between the three periods using the exact Wilcoxon test. We considered the month of detection of the outbreak to allocate them to each period.

All statistical analyses were performed using SAS 9.1 software (SAS Institute, Cary, North Carolina, United States). A p value 0.05 was considered statistically significant.

\section{Results}

Between August 2004 and December 2010, 45 distinct VRE outbreaks occurred in 21 of the 38 AP-HP hospitals, (16 of the 23 AC hospitals, and five of the 15 RLTC hospitals). Eight hospitals experienced a single outbreak, whereas eight hospitals experienced two outbreaks, two hospitals three outbreaks, two hospitals four outbreaks and one hospital seven outbreaks. Most outbreaks occurred on intensive care $(n=12)$, geriatrics $(n=10)$, digestive surgery $(n=6)$, and nephrology $(n=5)$ wards.

The 45 outbreaks comprised 533 cases, with a ratio of infected to colonised patients of $1: 6$. Most infections were urinary tract infections ( $51 \%)$, bacteraemias (15\%) and peritoneal infections (13\%).

The only species involved in these outbreaks was $E$. faecium. The gene encoding vancomycin resistance was vanA in 41 outbreaks and van $B$ in four outbreaks. Within each outbreak, the VRE strains shared the same PFGE pattern. PFGE patterns of the VRE strains involved in the 23 outbreaks that occurred in periods 1 and 2, allowed us to distinguish 12 distinct strains (Figures 1 and 2).

The strain involved in the first outbreak (112 cases), whose unusual antibiotic susceptibility pattern for a vanA genotype has been previously described [7], was also involved in nine other outbreaks affecting a total of eight distinct hospitals (Figures 1 and 2). The temporal overlap between the 10 outbreaks caused by this strain, as well as frequent links between the hospitals involved, strongly suggested inter-hospital dissemination (Figure 3). 
Observed cases and predicted values of monthly vancomycin-resistant Enterococcus cases before and after implementation of the infection control programme, Assistance Publique-Hôpitaux de Paris, August 2004-December 2010 ( $\mathrm{n}=533$ )

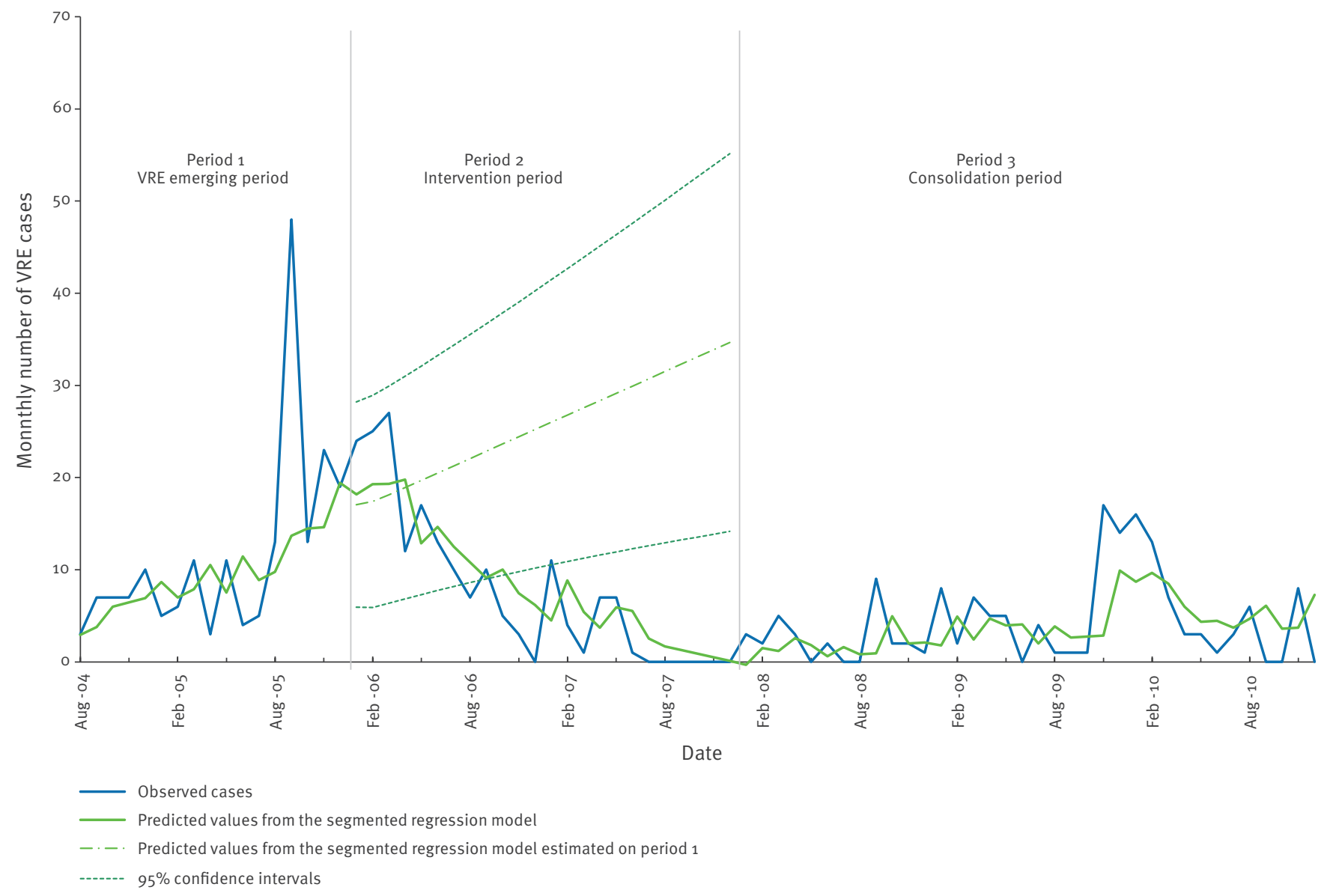

VRE: vancomycin-resistant Enterococcus.

Comparisons between the three periods

Figure 4 shows the time series analysis of the monthly VRE cases from August 2004 to December 2010 and the predicted values from the segmented regression model (with a first-order autoregressive error) for period 1 (August 2004 to December 2005), period 2 (January 2006 to December 2007) and period 3 (January 2008 to December 2010), i.e. from before until after the implementation of the enhanced control measures. During period 1, the estimated number of VRE cases increased significantly by 0.8 cases per month $(95 \% \mathrm{Cl}: 0.3$ to 1.3, $\mathrm{p}=0.001$ ) and was estimated at 2.9 in August 2004 and 19.4 in December 2005. During period 2, the number of VRE cases decreased by 0.7 cases per month ( $95 \% \mathrm{Cl}:-0.9$ to -0.5 , p<0.001) resulting in a significant trend change between the two periods of -1.5 cases per month ( $95 \% \mathrm{Cl}:-2.1$ to -0.9, pro.001). The estimated number of VRE cases decreased from 18.2 cases in January 2006 to 0.1 cases in December 2007. If no intervention had occurred, the number of VRE cases would have been expected to exceed 34 cases per month in period 2, and the predicted lower limit of the $95 \% \mathrm{Cl}$ forecast would have been greater than the observed number of VRE cases after November 2006 (see Figure 4 and the predicted values for period 2 if no intervention had occurred). In period 3 , when the VRE programme was routinely applied by local teams, the number of index cases was a little higher than in period 2, particularly between April and December 2009 , and one of the outbreaks was caused by delayed and incomplete implementation of bundle measures (see peak between November 2009 and February 2010 in Figure 4). Still, the number of observed cases remained markedly lower than the predicted lower limit of the $95 \% \mathrm{Cl}$ forecast.

If the mean number of new outbreaks of VRE per month did not decrease significantly over the three periods (o.8, 0.4 and 0.6 cases per month, respectively, in periods 1,2 and 3), the median number of cases per outbreak was 9.0 (IQR: 4.0-37.0) in period 1 and 4.0 (IQR: $2.0-8.0)$ in periods 2 and 3 , respectively $(p=0.027)$.

\section{Discussion}

This prospective multicenter study, carried out in the largest public multi-hospital institution in France, 
assessed the positive impact of an institutional control programme on the evolution of VRE outbreaks. The main result of the programme was the progressive and significant decrease in the overall number of new VRE cases in the AP-HP hospitals in the Paris region in 2006-07 (Intervention period, period 2), i.e. after implementation of a specific control programme. This decrease contrasts with the continuing increase that prevailed in 2004-05 (VRE emerging period, period 1), when French guidelines aiming at controlling cross transmission of endemic multidrug-resistant bacteria such as MRSA were used. Most importantly, the progress made during the intervention period lasted during the following Consolidation period of three years (period 3). Moreover, the median number of cases per outbreak was significantly lower after implementation of the specific control programme.

Our study has potential limitations since it was not a randomised, controlled trial aiming at assessing causality between intervention and outcome. The rapid spread of VRE triggered quick and strong actions to control the phenomenon at the institutional level, making randomised intervention impossible. However, the fact that the strength and nature of the enhanced measures implemented in periods 2 and 3 differed markedly from those in period 1, as well as the length of the study and the number of points of measurements are a justification to consider this study as a quasi-experimental study with pre-test and post-test periods [19].

Vancomycin consumption remained unchanged from 2003 to 2010, around 12 defined daily doses per 1,000 days of hospitalisation, and thus could not have influenced the decline in VRE cases (data not shown).

Bundle measures similar to those implemented in period 2 and sustained in period 3 have been associated with control of VRE outbreaks in individual hospitals in areas where VRE are emerging and not yet endemic $[9,20,21]$. Our study suggests that such measures can suppress VRE emergence by controlling outbreaks at the level of a large institution that covers a region with more than 10 million inhabitants.

The results obtained with the VRE programme are due to the implementation of a bundle of new additional measures, more extensive than the barriers precautions used before, notably stopping transfer of VRE patients and cohorting patients with dedicated nursing staff. Since we implemented all parts of the bundle measures at the same time in period 2, it is not possible to delineate the respective impact of the individual activities. Stopping the transfer of VRE cases and the transfer of contact patients within and between hospitals was most likely crucial for decreasing VRE spread in our institution. Colonisation pressure, i.e. the number of colonised patients present in a given unit, has been found to be an important variable affecting VRE acquisition [22]. Cohorting patients with dedicated nursing staff in three different sections is advocated to minimise VRE cross-contamination [23]. Implementation of cohorting required a strong and sustained involvement of chief nurses and heads of departments, as well as of administrators. The financial implications of such measures have been discussed by Ridwan et al: dedicated nursing staff, costs of surveillance cultures and molecular typing, of gowns and disinfection procedures, loss of admissions [23].

Screening contact patients has been emphasised by several authors $[5,20,21,24]$. Indeed, it is known that VRE-colonised patients outnumber infected patients several-fold [24]. The ratio found in our study $(6: 1)$ is lower than in several other studies (from 7:1 to 20:1) $[21,24]$. Screening in our study was focused on identifiable contact patients, i.e. any patient whose stay overlapped with the stay of a VRE case for at least one day in the same unit; a larger screening strategy could explain the higher ratio reported elsewhere. A large majority (36/45) of the outbreaks reported in this present study included at least one clinical infection. The remaining nine contained only colonised cases and could have been designated as clusters of colonisations. Since faecal VRE carriage may persist for months or years, systematic identification of contact patients both of infected and colonised cases was important to quickly isolate them in case of re-admission [25].

A rapid and strong intervention at the beginning of an outbreak is probably crucial in limiting its size and duration. The sooner the index case and the first secondary cases are isolated and cohorted and contact patients are identified and screened, the lower is the risk of additional cross-transmissions. Our study shows that, although VRE index cases continue to happen in our region due to admission of carriers [6], and although some secondary cases can occur when the identification of the index case is delayed, the outbreaks can be quickly controlled and the number of secondary cases strongly limited. This requires quick and sustained mobilisation of all stakeholders, particularly the infection control team, medical and nursing staff, microbiologists and hospital administrators [9]. The strong commitment of the AP-HP institution, continuous coordination and support by the central infection control team, as well as a continuous feedback stimulated the efforts made in each hospital. In December 2006, the AP-HP programme was extended by the health authorities to cover all of France, and the rate of VRE in E. faecium was maintained at a very low level (o.8\%) and even decreased in France between 2005 and 2009 as shown by the European Antimicrobial Resistance Surveillance Network [3].

The proactive strategy to control VRE can be also applied successfully in the control of carbapenemaseproducing enterobacteria $[26,27]$, another emerging multidrug-resistant bacterium, and should be promoted at the European level as suggested by several authors $[23,28]$. A sustained and coordinated strategy, set up in 1993 in our institution, has led to a 
continuous decrease of MRSA rates, particularly since 2001 [10]. It is interesting to note that VRE began to spread in our institution in 2004 despite the MRSA programme, and was contained only when a specific VRE programme has been implemented. Such institutional programmes, based on a coordinated policy, are efficient ways to bring together and motivate hospital staff and managers, and to promote quality and safety in healthcare.

\section{Acknowledgments}

We thank Hervé Blanchard, Michel Denis, Catherine Doit, Jean-Michel Guérin, Guillaume Kac, Christine Lawrence, Véronique Moulin, Martine Rouveau from the Assistance Publique - Hôpitaux de Paris infection control teams and Michèle Huang, Ségolène Neuville, Catherine Monteil, Roland Gonin and Jean-Marc Boulanger from central administration for their commitment in VRE outbreaks control. We are indebted to Antoine Andremont, Patrick Berche, Edouard Bingen, Jean-Louis Gaillard, Laurent Gutmann, Marie-Hélène Nicolas-Chanoine, Patrice Nordmann, Jean-Claude Petit, Bertrand Picard, Claire Poyart and Marie-José Sanson-Le Pors for organising the laboratory-based survey and VRE screening.

\section{References}

1. National Nosocomial Infections Surveillance System. National Nosocomial Infections Surveillance (NNIS) System Report, data summary from January 1992 through June 2004, issued October 2004. Am J Infect Control. 2004;32(8):470-85.

2. Tenover FC, Weigel LM, Appelbaum PC, McDougal LK, Chaitram J, McAllister S, et al. Vancomycin-resistant Staphylococcus aureus isolate from a patient in Pennsylvania. Antimicrob Agents Chemother. 2004;48(1):275-80.

3. European Centre for Disease Prevention and Control (ECDC). Antimicrobial resistance surveillance in Europe 2009. Annual Report of the European Antimicrobial Resistance Surveillance Network (EARS-Net). Stockholm: ECDC; 2010. Available from: http://www.ecdc.europa.eu/en/publications/Publications/ Forms/ECDC_DispForm.aspx?ID $=580$.

4. McGowan JE. Debate-guidelines for control of glycopeptideresistant enterococci (GRE) have not yet worked. J Hosp Infect. 2004;57(4):281-4.

5. Ostrowsky BE, Trick WE, Sohn AH, Quirk SB, Holt S, Carson LA, et al. Control of vancomycin-resistant enterococcus in health care facilities in a region. N Engl J Med. 2001;344(19):1427-33.

6. Fortineau N, Bourdon N, Leclercq R, Vachée A, Delarbre $J-M$, Maugat $S$, et al. Low carriage of vancomycin-resistant enterococci in the digestive tract of French hospitalised patients: a nationwide prospective study in 2006. J Hosp Infect. 2011;77(2):179-81.

7. Naas T, Fortineau N, Snanoudj R, Spicq C, Durrbach A, Nordmann P. First nosocomial outbreak of vancomycinresistant Enterococcus faecium expressing a VanD-like phenotype associated with a vanA genotype. J Clin Microbiol. 2005;43(8):3642-9.

8. Lesens O, Mihaila L, Robin F, Baud O, Romaszko JP, Tourniac O, et al. Outbreak of colonization and infection with vancomycinresistant Enterococcus faecium in a French university hospital. Infect Control Hosp Epidemiol. 2006;27(9):984-6.

9. Lucet JC, Armand-Lefevre L, Laurichesse JJ, Macrez A, Papy E, Ruimy R, et al. Rapid control of an outbreak of vancomycin-resistant enterococci in a French university hospital. J Hosp Infect. 2007;67(1):42-8.

10. Jarlier V, Trystram D, Brun-Buisson C, Fournier S, Carbonne A, Marty L, et al. Curbing methicillin-resistant Staphylococcus aureus in 38 French hospitals through a 15-year institutional control program. Arch Intern Med. 2010 22;170(6):552-9.

11. Astagneau P, Costa Y, Legrand P, Lucet J, Marty L, Prieur B. Maîtrise de la diffusion des bactéries multirésistantes aux antibiotiques. [Control of the spread of multiple-antibiotic resistant bacteria]. Paris: Ministère de l'Emploi et de la Solidarité, Secrétariat d'Etat à la Santé et à l'Action Sociale, Comité Technique National des Infections Nosocomiales;1999. French.

12. Brown DF, Walpole E. Evaluation of selective and enrichment media for isolation of glycopeptide-resistant enterococci from faecal specimens. J Antimicrob Chemother. 2003;51(2):289-96.

13. Eigner U, Fahr A, Weizenegger M, Witte W. Evaluation of a new molecular system for simultaneous identification of four Enterococcus species and their glycopeptide resistance genotypes. J Clin Microbiol. 2005;43(6):2920-2.

14. Société Française de Microbiologie. Comité de l'Antibiogramme de la Société Française de Microbiologie. Communiqué 2006. [Statement 2006]. Paris: 2006. French. Available from: http://www.sfm-microbiologie.org/UserFiles/file/CASFM/ casfm_2006.pdf.

15. Murray BE, Singh KV, Heath JD, Sharma BR, Weinstock GM. Comparison of genomic DNAs of different enterococcal isolates using restriction endonucleases with infrequent recognition sites. J Clin Microbiol. 1990;28(9):2059-63.

16. Tenover FC, Arbeit RD, Goering RV, Mickelsen PA, Murray BE, Persing DH, et al. Interpreting chromosomal DNA restriction patterns produced by pulsed-field gel electrophoresis: criteria for bacterial strain typing. I Clin Microbiol. 1995;33(9):2233-9.

17. Morrison D, Woodford N, Barrett SP, Sisson P, Cookson BD. DNA banding pattern polymorphism in vancomycin-resistant Enterococcus faecium and criteria for defining strains. J. Clin. Microbiol. 1999;37(4):1084-91.

18. Wagner AK, Soumerai SB, Zhang F, Ross-Degnan D. Segmented regression analysis of interrupted time series studies in medication use research. J Clin Pharm Ther. 2002;27(4):299-309.

19. Harris AD, Bradham DD, Baumgarten M, Zuckerman IH, Fink $J C$, Perencevich EN. The use and interpretation of quasiexperimental studies in infectious diseases. Clin Infect Dis. 2004;38(11):1586-91.

20. Christiansen KJ, Tibbett PA, Beresford W, Pearman JW, Lee RC, Coombs GW, et al. Eradication of a large outbreak of a single strain of vanB vancomycin-resistant Enterococcus faecium at a major Australian teaching hospital. Infect Control Hosp Epidemiol. 2004;25(5):384-90.

21. Kurup A, Chlebicki MP, Ling ML, Koh TH, Tan KY, Lee LC, et al. Control of a hospital-wide vancomycin-resistant Enterococci outbreak. Am J Infect Control. 2008;36(3):206-11.

22. Bonten MJ, Slaughter S, Ambergen AW, Hayden MK, van Voorhis J, Nathan C, et al. The role of "colonization pressure" in the spread of vancomycin-resistant enterococci: an important infection control variable. Arch Intern Med. 1998;158(10):1127-32.

23. Ridwan B, Mascini E, van Der Reijden N, Verhoef J, Bonten $M$. What action should be taken to prevent spread of vancomycin resistant enterococci in European hospitals? BMJ. 2002;324(7338):666-8.

24. Calfee DP, Giannetta ET, Durbin LJ, Germanson TP, Farr BM. Control of endemic vancomycin-resistant Enterococcus among inpatients at a university hospital. Clin Infect Dis. 2003:37(3):326-32.

25. Byers KE, Anglim AM, Anneski CJ, Farr BM. Duration of colonization with vancomycin-resistant Enterococcus. Infect Control Hosp Epidemiol. 2002;23(4):207-11.

26. Kassis-Chikhani N, Saliba F, Carbonne A, Neuville S, Decre D, Sengelin C, et al. Extended measures for controlling an outbreak of VIM-1 producing imipenem-resistant Klebsiella pneumoniae in a liver transplant centre in France, 20032004. Euro Surveill. 2010;15(46). Available from: http://www. eurosurveillance.org/ViewArticle. aspx?Articleld=19713

27. Carbonne A, Thiolet JM, Fournier S, Fortineau N, KassisChikhani N, Boytchev l, et al. Control of a multi-hospital outbreak of KPC-producing Klebsiella pneumoniae type 2 in France, September to October 2009. Euro Surveill. 2010;15(48). Available from: http://www.eurosurveillance.org/ViewArticle. aspx?Articleld $=19734$

28. Carmeli Y, Akova M, Cornaglia G, Daikos GL, Garau J, Harbarth $\mathrm{S}$, et al. Controlling the spread of carbapenemase-producing Gram-negatives: therapeutic approach and infection control. Clin Microbiol Infect. 2010;16(2):102-11. 